\title{
O diário de leitura: subjetividade na sala de aula
}

The reading journal: subjectivity in the classroom

\section{Sheila Oliveira Lima* (i)}

sheilalima@uel.br

http://orcid.org/0000-0002-0993-8228

\section{Patrícia Cardoso Batista**}

patty_jbt@hotmail.com

http://orcid.org/0000-0002-3096-6178

Tatiele Jesus Faria ${ }^{* \star *}$

tatielefaria@gmail.com

http://orcid.org/0000-0001-9473-7748

\section{Resumo}

O trabalho com a leitura, quando considera a subjetividade, demanda a utilização de instrumentos que permitam acolher as impressões do aluno leitor. Para isso, é necessário pensar em propostas aplicáveis ao ensino e que considerem esse aspecto do ato de ler. Em vista disso, este relato de experiências tem como objetivo discutir o uso do diário de leitura em sala de aula a partir de experiências diversas, sendo duas realizadas na Educação Básica e uma no Ensino Superior. Como procedimentos teóricos e metodológicos, baseamo-nos nos estudos de Rouxel (2012-2013); Jouve (2013); Petit (2009), dentre outros. Os resultados evidenciaram que o diário abre um espaço para o aluno se colocar como protagonista da leitura e favorece a construção de uma relação pessoal com a obra, que pode ser acessada parcialmente pelo professor. Portanto, trata-se de uma ferramenta com potencial para o trabalho na perspectiva da subjetividade em sala de aula.

Palavras-chave: Diário de leitura; Subjetividade; Práticas leitoras; Literatura; Formação de leitores.

* Universidade Estadual de Londrina (UEL), Londrina, PR, Brasil.

** Universidade Estadual de Londrina (UEL), Londrina, PR, Brasil.

*** Secretaria Estadual de Educação do Paraná - SEED/PR, Colégio Estadual Barão do Rio Branco, Londrina, PR, Brasil.

\section{LINHA DÁGUA}




\begin{abstract}
The work with reading, when considering subjectivity, requires the use of instruments that enable accepting the student reader's impressions. Thus, it is necessary to think about proposals that are applicable to teaching and that take into consideration this aspect of the act of reading. Hence, this experience report aims at discussing the use of the reading journal in the classroom, from different experiences, two of which were carried out in Basic Education and one in Higher Education. As theoretical and methodological procedures, the study draws on Rouxel (2012-2013); Jouve (2013); and Petit's studies (2009), among others. The results showed that the journal opened a space for the student to place himself as the protagonist of reading, supporting their construction of a personal relationship with the work, which can be partially accessed by the teacher. Therefore, it is a tool with potential for work in the perspective of subjectivity in the classroom.
\end{abstract}

Keywords: Reading journal; Subjectivity; Reading practices; Literature; Education of readers.

\title{
Introdução
}

O trabalho com a leitura em sala de aula, seja na universidade ou na escola, exige que o professor recorra a pressupostos teóricos e metodológicos que amparem a sua prática, de modo a buscar uma maior eficácia da atividade leitora nos diversos processos de formação, do mais elementar ao mais complexo. Por essa razão, explicitamos, de saída, que, neste artigo, consideramos que a subjetividade é uma parte relevante da constituição da leitura, pois o que toca e afeta o leitor diverge consideravelmente entre os indivíduos. A esse respeito, Jouve (2013, p. 53) expõe que “[...] cada um projeta um pouco de si na leitura, por isso a relação com a obra não significa somente sair de si, mas também retornar a si." Como somos sujeitos únicos, com histórias de vida também distintas, é notável que uma mesma leitura provoque efeitos diferentes e evoque impressões particulares, fato a ser considerado nas práticas de ensino.

Ao encontro das ideias de Jouve, a antropóloga francesa Michèle Petit (2009) considera que a leitura, especialmente a da obra literária, tem papel fundamental na elaboração da subjetividade do leitor, na medida em que se constitui uma experiência muitas vezes transformadora dos posicionamentos do indivíduo em relação a si e ao seu entorno. Também Langlade (2013) reforça tal concepção, assumindo que há, no processo da leitura, um "[...] movimento duplo de implicação e de distância, em que o investimento emocional, psicológico, moral e estético inscreve a obra como uma experiência singular" (LANGLADE, 2013, p. 37). Isto é, o ato de ler, por se constituir tão vinculado ao campo da subjetividade, pode impactar a própria vida do seu leitor, sendo fundamental observar tal situação nas práticas escolares ligadas à leitura de literatura.

Tendo em vista que a leitura evoca a subjetividade do leitor e que isso deve ser considerado em sala de aula, temos a necessidade de pensar em ferramentas que possam nos ajudar a colocar em prática algo que proporcione aos alunos-leitores sua vinculação na

\section{LINHA DÁGUA}


construção dos sentidos. Isso nos leva a questionar o ensino centrado nas atividades rígidas e fechadas, que desconsideram o lugar do sujeito no processo da leitura, pelo fato de proporem abordagens marcadas por elaborações padronizadas e padronizadoras, como é o caso dos resumos, provas do livro, fichas de leitura etc. Entretanto, apesar de haver amplas discussões sobre a insuficiência dessas práticas, por serem redutoras da leitura e causarem o distanciamento do educando da obra literária ou aversão ao livro, observamos que elas ainda são ainda muito frequentes no sistema educacional.

Nesse contexto, faz-se necessária a construção de novas propostas, no sentido da legitimação da leitura como direito, fator de humanização, transformação social e cultural dos alunos, e que dediquem maior atenção à subjetividade do leitor. Enxergarmos, nessa linha, o diário de leitura como um instrumento capaz de captar as impressões dos estudantes motivadas pelo texto e de autorizar a construção de uma relação mais pessoal com a obra, mostrando-se como uma atividade de leitura capaz de implicar o leitor e motivar seu engajamento com o texto.

Neste artigo, enfocaremos as possíveis abrangências do diário de leitura, uma vez que no caso da Educação Básica, ele pode dar indícios de como o estudante aprende a ser leitor, além de auxiliar o professor a compreender as particularidades do processo de leitura para que possa melhor planejar a sua intervenção. Ademais, apresenta-se como um espaço para o aluno expressar sua subjetividade e sentir-se implicado na leitura. Já no Ensino Superior, notadamente nos cursos de licenciatura, o diário permite que o docente em formação vivencie o processo subjetivo de leitura, podendo, inclusive, cogitar a sua implementação na sua futura prática docente. Trata-se de um instrumento flexível, que pode ser utilizado com objetivos diversos, e que permite compreender mais e melhor o percurso do leitor durante a leitura, tendo em vista que nele se admitem e se incentivam a inscrição das subjetividades.

Diante disso, este artigo tem como objetivo discutir o uso do diário de leitura em sala de aula a partir de experiências práticas realizadas na Educação Básica e no Ensino Superior, contextos cujas ações enfocaram diferentes aspectos da subjetividade leitora que esse instrumento pode trazer à tona. Para tanto, as problematizações aqui presentes basearam-se em Rouxel $(2012 ; 2013 b)$, para quem o diário de leitura representa um ganho para a formação de leitores, Jouve (2002), criador de uma proposta metodológica para ensino da leitura e da literatura marcada pela valorização da subjetividade leitora, e Petit (2009), defensora do papel do leitor na construção de sentidos do texto.

\section{0 diário de leitura}

Muito se tem discorrido sobre a importância da leitura e o seu valor para a aquisição de conhecimentos que extrapolem os muros da escola. Entretanto, tem sido frequente a carência de práticas que a tornem viva entre alunos e seus professores. Langlade (2013), ao discorrer sobre a maneira como a leitura, em especial a literária, é vista e praticada dentro da sala de aula,

\section{LINHA DÁGUA}


destaca o que ele nomeia de marginalização da subjetividade do leitor e como esse fator é considerado exitoso pelas instâncias escolares, uma vez que, toda experiência pessoal, subjetiva, é apreciada como "elementos parasitas que falseiam, embaçam e emaranham a recepção de uma obra a ponto de lançá-la para fora do campo da literatura" (LANGLADE, 2013, p. 25).

O referido autor defende que as reações subjetivas não são excludentes, pois não têm como objetivo banir as construções de sentido para fora da literatura, ao contrário, seriam catalisadoras de leitura, porque alimentariam o trajeto interpretativo do leitor até sua dimensão reflexiva. É esse processo subjetivo que possibilita a troca recíproca e contínua entre a interioridade do leitor e a obra.

Para que esse processo se faça presente na escola, a pesquisadora francesa Annie Rouxel (2012) aborda a importância de se contemplarem atividades que ofereçam acesso à expressão subjetiva, como o diário de leitura, e defende que seu uso pode ser profícuo para a formação de leitores, pois introduz um espaço para o estudante colocar-se como leitor e expressar sua subjetividade, aspecto a ser mais considerado em sala de aula. $\mathrm{O}$ uso desse instrumento, de acordo com a referida autora, proporciona aos educandos sensações que irão aguçar a imaginação, além de ser um objeto que compõe a identidade do sujeito-leitor, pois, no ato de ler e reler a leitura realizada, o aluno passa a se reconhecer enquanto leitor.

Para Rouxel (2012), formar leitores literários exige uma relação viva com o texto, e isso implica o seu investimento subjetivo, o qual completa o sentido da obra. Por isso, defende-se que a leitura literária não se reduz a uma atividade cognitiva, sendo também fortemente marcada pelo afeto.

Nessa perspectiva, a autora diferencia a leitura em duas categorias, sendo elas a analítica e a cursiva. A leitura analítica, privilegiada na escola, é aquela lenta, focada nos detalhes do texto e que anseia por uma interpretação consensual. Entretanto, essa abordagem desconsidera o leitor e sua subjetividade, consequentemente não garante a construção de uma relação intensa do aluno-leitor com o texto. Tendo em vista a identificação dessa problemática, segundo a autora, desde 2001, a França mudou sua concepção no trabalho com a literatura e adotou a leitura cursiva em seu currículo oficial, o que consiste em privilegiar a subjetividade do leitor em seu encontro com o texto, diferindo da analítica, que privilegia os aspectos textuais. A leitura cursiva é autônoma e pessoal, convida o aluno-leitor a se identificar com a obra e apreendê-la de forma singular. Essa leitura autoriza o sujeito a identificar-se com o texto, criando assim, uma relação pessoal com ele. Nessa perspectiva, podemos dizer que a construção do diário de leitura se aproxima da leitura cursiva, pois como esta, introduz um espaço de liberdade ao leitor.

Em consonância, Todorov (2010), em A literatura em perigo, aponta que o ensino de literatura na escola tem focado muito em questões teóricas, tais como a opinião dos críticos e a análise estrutural, em detrimento da abordagem da própria obra ou do modo como ela atinge seu leitor em particular. Para ele, as obras literárias devem ser lidas e discutidas antes de serem

\section{LINHA DÁGUA}


classificadas e periodizadas. Quanto aos elementos estruturais, estes podem ser abordados, contudo, não podem "substituir o sentido da obra, que é o seu fim" (TODOROV, 2010, p. 31). A leitura da obra literária propriamente dita é o que proporciona uma experiência benéfica na constituição de leitores, por isso não pode ficar em segundo lugar na escola.

Nesse sentido, Todorov (2010) salienta que o leitor, por não ser um profissional da área literária, se dispõe a ler literatura porque a atividade consiste em um meio que o leva a "compreender melhor o homem e o mundo, a encontrar elementos que enriqueçam sua vida e, assim, poder compreender melhor também a si mesmo" (TODOROV, 2010, p. 33). Entretanto, muitas vezes, o curso de Letras não propõe a reflexão sobre o texto literário voltada para o ensino, consequentemente seus licenciandos levam para a escola as práticas que desenvolveram na universidade. Assim, parece-nos fundamental a utilização de ferramentas diversas no curso superior, de modo a propiciar atitudes diferentes perante a prática pedagógica e fazendo notar que, na escola, não estamos formando especialistas em estudos literários, mas apresentando a literatura como fonte rica de conhecimento sobre o homem.

Em vista disso, da universidade à escola, o diário de leitura pode ser um instrumento rico para trabalhar o texto na perspectiva da leitura cursiva. A esse respeito, Rouxel (2012) expõe que o diário permite observar a existência de uma relação pessoal com o livro e traços do processo de construção identitária. Isto é, permite que a subjetividade do leitor venha à tona, o que é importante quando se trata de literatura, pois esta propicia uma experiência humana de forte envolvimento simbólico e afetivo. É claro que os alunos não expressam tudo daquela leitura privada em seus diários, pois, segundo Rouxel (2012, p. 277), “Da experiência de leitura somente alguns fragmentos chegam à consciência do leitor e se pode duvidar da possibilidade de se transmitir tal experiência." Além disso, os educandos podem escolher o silêncio e o que querem relatar ou não, uma vez que, dependendo do objetivo pedagógico, o diário poderá ser lido pelo professor.

Na escrita do diário, é possível que o aluno revele traços da sua leitura subjetiva e íntima, trazendo alguns aspectos, como: gostos literários, considerações pessoais, identificação com as personagens, cópia de trechos marcantes, referência a outras obras, pontos relacionados a sua compreensão leitora, relação da obra com sua existência etc. Trata-se de uma apropriação pessoal dos textos, que, segundo Rouxel (2013b), geralmente não tem espaço no ensino, por não ter o hábito de legitimar o que não é estritamente textual.

Ainda nos referenciando em Rouxel (2012, p. 278), consideramos potencializador dos processos de engajamento dos leitores com a literatura o restabelecimento do "sujeito no coração da leitura", acolhendo suas impressões primeiras sobre os textos, as quais tendem manterem-se vivas durante todo o trabalho interpretativo. Para a autora, mais importante que uma interpretação impecável do texto é o aproveitamento pessoal da obra pelo leitor, propiciando que ele a relacione com a sua vida e a utilize para pensar o mundo. A pesquisadora destaca que a obra ganha sentido e se inscreve na vida do sujeito quando um vínculo é estabelecido entre o universo do leitor e o universo da obra. Em vista disso, ela defende que

\section{LINHA DÁGUA}


não se trata de desconsiderar a dimensão formal e objetivável do texto, mas de acolher os afetos provocados por ele e incentivar os alunos a descobrir dilemas pessoais na leitura. Para Rouxel (2013a, p. 178), "Se desejamos que a cultura literária seja efetiva - ativa - (e não uma simples finalidade do ensino), importa que a leitura seja para o aluno um acontecimento. É necessário, portanto, acolher a subjetividade e não a censurar." Com base no argumento do acolhimento dos afetos, surgem as propostas de trabalho com o diário de leitura nas experiências aqui relatadas.

Ainda dentro do debate sobre a relevância da subjetividade nas práticas leitoras, Petit (2009) considera que o leitor, a partir das palavras do autor, constrói seu próprio texto e o constitui com suas próprias palavras. Isto é, ele dialoga com o texto, opera sobre ele e o reescreve, de modo que altera o sentido, faz o que bem entende, distorce, reemprega, introduz variantes, deixa de lado os usos corretos. Da mesma forma que o leitor trabalha em cima da leitura do texto, ele é também transformado por ela.

E é nesse fundir que a leitura se confirma como elemento de construção social, propondo ao leitor novas indagações, questionamentos, inquietações e perplexidades. A obra está completa quando tem a capacidade de promover a reflexão sobre algo com alguém, em síntese, quando a interação se dá entre o autor, o texto e o leitor. Assim, somente quando se estabelece esse colóquio é que a obra literária participa como elemento constitutivo de uma sociedade, por conseguinte, como elemento social de expressão de identidade cultural.

\section{Experiências práticas da escola à universidade: desafios, possibilidades e tentativas}

Neste tópico, relataremos experiências realizadas por diferentes docentes com a aplicação do diário de leitura em sala de aula, sendo duas vivenciadas em escolas de Ensino Fundamental e uma no Ensino Superior. Trata-se de propostas iniciais, realizadas de formas diversas, e que podem ser modificadas de acordo com o contexto e o propósito da atividade, uma vez que não defendemos a existência de fórmulas, mas sim de estratégias que considerem o papel da subjetividade e dos afetos no ensino. Logo, apresentam-se, neste artigo, as possibilidades e os desafios na utilização desse instrumento em sala de aula, expondo como, a partir dele, o professor pode entender um pouco mais sobre a formação do aluno-leitor, propiciando, também, espaço para a expressão da subjetividade.

\subsection{O diário de leitura na Educação Básica 1: espaço de aprendizagem e expressão das subjetividades}

A primeira prática apresentada aborda a utilização do diário de leitura na disciplina de Língua Portuguesa, no $8^{\circ}$ ano, numa escola particular no Paraná, efetuada no ano de 2020. Com

\section{LINHA DÁGUA}


o objetivo de realizar a escrita do diário, elaboraram-se orientações para melhor compreensão da proposta por parte dos alunos, uma vez que eles estavam habituados a realizar apenas resumos dos livros como atividade relacionada a suas leituras, sem haver espaço para expressar suas considerações pessoais. Para tanto, sugeriu-se a adoção da primeira pessoa, registro da data de início e término da leitura; título da obra e informações sobre o autor; aspectos que mais chamaram a atenção na obra, como pontos fortes e citação interessante, seguido de uma análise crítica e conclusão.

Além disso, propôs-se a realização de anotações antes, durante e depois da leitura, como forma de sinalizarem para si próprios o processo interpretativo, podendo reconhecer os movimentos de inferências e correções destas. No item denominado "antes da leitura", os alunos poderiam escrever suas primeiras impressões sobre a obra e apresentar suas expectativas, dizendo sobre o que acreditavam que trataria o texto e se tinham vontade de lê-lo. Em "durante a leitura", a sugestão foi o registro de tudo que achassem interessante e os sentimentos despertados pela obra. Ao final, em "depois da leitura", a intenção era expressar o que haviam sentido ao terminar de ler, se julgavam produtiva a experiência com o texto e o que diriam para a próxima pessoa que ingressasse na leitura do mesmo livro.

Para a realização da proposta, os estudantes utilizaram um caderno e o dividiram ao meio, sendo convidados a nomeá-lo e ilustrá-lo. Entretanto, observou-se, pelas produções resultantes, que não haviam se apropriado de fato do objeto como esperado pela professora, já que a maioria dos alunos se restringiu apenas à escrita, sem recorrer a outros recursos ou outras linguagens para registrar e expressar suas leituras.

Em relação à avaliação do diário, decidiu-se, em conjunto com os alunos, que ela faria parte das atividades realizadas durante o ano e que o caderno seria recolhido e lido pela docente. Com isso, foi possível perceber maior adesão, na medida em que se viram instados a realizar a atividade em troca de uma nota. Por outro lado, porém, tal decisão abriu brechas para o cumprimento da atividade de forma mecânica, como observado em alguns diários que, mesmo com as orientações aqui reproduzidas, se restringiram apenas à síntese objetiva do livro.

Ainda é importante ressaltar que, num primeiro momento, tinha-se a intenção de acompanhar de perto as produções dos educandos, o que se tornou inviável em face da suspensão das aulas presenciais devido à pandemia de COVID-19. Nessas condições, o diário de leitura passou a ser entregue apenas uma vez ao final de cada bimestre, o que dificultou a supervisão da docente, pois ficaram impossibilitados os diálogos que levariam a um melhor desenvolvimento da proposta. Logo, faltaram momentos para explorar mais o gênero diário, levando alguns alunos a se restringirem a descrições impessoais das obras, conforme já estavam habituados.

Para além das considerações iniciais sobre o instrumento, apresenta-se como se deu o trabalho em sala de aula, uma vez que a implementação do diário ocorreu concomitantemente com outras estratégias que visaram à construção de uma boa relação entre texto e aluno. Sendo assim, para o primeiro registro no diário, foi realizada a leitura em voz alta do conto "Tchau",

\section{LINHA DÁGUA}


da Lygia Bojunga Nunes. Para a realização dessa prática, partiu-se dos pressupostos de Pastorello (2015) de que a leitura em voz alta toca o outro, e, ao se sentir tocado, o sujeito tende a querer repetir a experiência que lhe propiciou prazer, o que o levaria a ir em busca do texto. Nesse sentido, a intenção foi que os estudantes se interessassem pela obra e buscassem realizar a leitura de outros contos presentes nela. Logo, a prática obteve os resultados esperados porque o texto lido moveu os estudantes a buscarem outros textos da autora em questão. Houve até o questionamento de uma aluna a respeito do final da história, duvidando que houvesse terminado, pois havia observado que o livro se prolongava para além das páginas do conto, além de ter sofrido o impacto de um conteúdo diverso das convenções familiares, para as quais se entende que uma mãe jamais abandonaria os filhos para seguir num outro relacionamento amoroso. Diante disso, a aluna sentiu-se convocada a levar o livro para casa e explorar as histórias, na tentativa de comprovar se o que fora lido estava realmente inscrito no texto.

Além da leitura em voz alta, promoveram-se momentos para o compartilhamento em sala, para que os alunos pudessem expressar os sentimentos despertados. Essa atividade gerou muitas indagações e discussões sobre o texto, as quais foram explicitadas no diário de leitura também. Foi o caso do aluno E, que registrou: "Bom, eu gostei muito do livro, porque eu queria que a mulher voltasse e eles voltassem com o relacionamento. Porém ela foi embora e deixouos, eu não esperava por isso, porque a maioria dos livros termina em final feliz. Mas por um lado fiquei feliz, pois foi algo imprevisível." Esse relato diz muito sobre as histórias que o estudante tem lido e expõe o seu pouco contato com textos literários mais densos, difíceis, segundo Andruetto (2017), o que dá indícios sobre quais textos selecionar para as próximas aulas, uma vez que o desconforto causado pareceu ter sido um ponto interessante daquela história para o processo de formação daqueles leitores.

Em consonância, outros alunos mostraram admiração pelos autores trabalhados e indignação com os finais surpreendentes, menos frequentes em obras que circulam mais amplamente no mercado literário, vale dizer, na literatura de massa. Sendo assim, observou-se que os estudantes estavam acostumados com os finais felizes e previsíveis, típicos das obras mais comerciais (como contos de fadas adaptados ou certo ramo da literatura infanto-juvenil), pois, por meio de áudios enviados à professora ou de relatos escritos no diário, enfatizaram o incômodo com o final inesperado, muitas vezes, triste. Observa-se, em casos como esse, a descoberta paulatina, pelos alunos, de produções literárias marcadas pela densidade temática, as quais podem surpreendê-los pelas histórias e imaginários. Nesse percurso, o professor pode refletir sobre o ensino de leitura e sobre como interferir nos processos individuais, a partir dos depoimentos expressos por seus alunos.

Em outros relatos, como dito anteriormente, foi possível ler apenas uma síntese da história, evidenciando que os alunos não estavam acostumados a se colocarem enquanto protagonistas da leitura e expressarem suas opiniões. Desse modo, eles encontraram dificuldades em fazer os registros no diário durante o processo, tendo preferido expressar oralmente suas opiniões antes e durante a leitura, e escrevê-las somente ao terminarem. Logo, a proposta foi flexibilizada a fim de engajar os educandos e não tornar a atividade mais uma 
obrigação que submete a leitura ao estatuto apenas de dever. A partir dos resultados obtidos pela produção de tais grupos de alunos, foi possível perceber que a escrita, para eles, estava ligada a uma atividade escolar fechada e utilizada apenas como uma prova física de sua leitura das obras. Em contrapartida, o compartilhamento e a leitura em voz alta se mostraram atividades interessantes que geraram engajamento com o texto.

Nesse sentido, observou-se que promover a leitura na escola exige a adaptação de atividades conforme as potencialidades dos alunos, pois, de início, o mais importante é a construção de uma relação positiva com o ato de ler. Logo, faz-se necessário pensar e repensar constantemente a prática a fim de evitar atividades que tragam uma visão negativa da leitura literária. Por isso, é importante diversificar e observar as crenças dos educandos, para que possamos quebrá-las ou usá-las a favor do ensino. À vista disso, a promoção de práticas significativas é um desafio, mas os resultados são animadores, pois objetiva-se que os estudantes sigam apreciando autores, histórias ou a leitura no geral e levem isso para vida, não apenas para o cumprimento de uma tarefa.

A experiência mostrou que a partir dos relatos nos diários de leitura é possível conhecer mais sobre as preferências dos estudantes e as lacunas na compreensão do texto, pois alguns expressaram ou deixaram indícios de suas apreciações, como o aluno L, que, ao abordar o conto "Uma Galinha", de Clarice Lispector, ressaltou que a história termina com a personagem principal vivendo feliz com a família, não se atentando ao seu final trágico. Já o aluno E traz uma crítica ao livro O Mercador de Veneza, de Shakespeare: “o livro em si é muito bom, porém tem muitos personagens, não decorei todos". Aqui o estudante explicita a sua dificuldade em lidar com o texto teatral, parecendo não compreender a utilidade da listagem das personagens no início do volume.

Logo, os relatos no diário apresentam-se como importantes elementos para o professor pensar a prática pedagógica, seja para a seleção de textos ou para prestar o auxílio para o entendimento de obras mais complexas ou com as quais têm pouca familiaridade. Desse modo, o diário é uma forma de o docente acompanhar como o aluno está se relacionando com o texto e quais ações pode planejar para interferir de forma positiva. Ademais, durante o trabalho com o diário, os estudantes se mostraram mais engajados com a leitura literária, pois passaram a sentir-se motivados a compartilhar suas interpretações e opiniões sobre suas leituras com a docente. Notou-se, entretanto, a necessidade de trabalhar mais a prática da escrita, tornando-a menos entediante e principalmente, mais familiar para o alunado.

O diário de leitura foi uma forma de abandonar aquelas práticas que visam a atestar que o aluno leu e que desconsideram que o ato de ler em si já é suficiente. É uma maneira de aceitar e colocar em pauta no ensino que "Os textos que mais trabalham o leitor são aqueles em que algo passa de inconsciente a inconsciente. E isso nos escapará sempre, pelo menos em grande parte - felizmente" (PETIT, 2009, p. 184). Sendo assim, o uso do diário de leitura se mostrou uma ferramenta que admite não ser possível apreender todo o trabalho desenvolvido pelo aluno com o texto, mas que, mesmo assim, permanece uma atividade relevante, merecedora de seu

\section{LINHA DÁGUA}


lugar em nossas aulas, já que favorece as condições para a expressão da subjetividade leitora e para a vinculação com a leitura.

Vale ressaltar, ainda, que nem tudo do processo da leitura é possível apreender a partir dos registros dos diários, pois ela atua secretamente sobre o leitor e, de fato, é comum que este se cale sobre o essencial que emerge de si na leitura do texto, sobre como é perpassado pelo pensamento do outro e sobre como isso transforma o seu próprio pensamento. Isto é, a transformação interior não é facilmente analisável ou descritível pelo aluno-leitor.

\subsection{O diário de leitura na Educação Básica 2: leitores afetados}

A segunda prática com o diário de leitura aconteceu na disciplina de Língua Portuguesa, em uma escola estadual do Paraná, e fez parte do projeto de Mestrado Profissional PROFLETRAS, aplicado em 2019, com uma turma de 9. ${ }^{\circ}$ ano. A experiência com o diário compôs uma das etapas do projeto que possuía como objetivos expandir o horizonte do leitor a partir de textos literários canônicos, desenvolver no aluno o potencial crítico e oportunizar o contato com a leitura da literatura em sala de aula. (FARIA, 2020).

As atividades de intervenção foram desenvolvidas para leitura dos seguintes contos: Seminário dos Ratos, de Lygia Fagundes Telles; "O barril de Amontillado", de Edgar Allan Poe, com tradução de Samuel Titan Jr.; "Pai contra mãe", de Machado de Assis; A nova Califórnia, de Lima Barreto; "Uma vela para Dario", de Dalton Trevisan; e "A pequena vendedora de fósforos", de Hans Christian Andersen, com tradução de Viviane Da Rocha Prado.

A leitura dos contos aconteceu de maneira compartilhada em sala de aula, seguida da aplicação de atividades e discussões, a fim de proporcionar aos leitores o encontro com obras mais complexas, ambíguas e com o objetivo da realização de leituras mais minuciosa, relendo passagens e discutindo possíveis interpretações, considerando, assim, as subjetividades leitoras. Nesta perspectiva, os alunos receberam, antes da primeira atividade de leitura, um caderno destinado à realização de anotações sobre as impressões a respeito dos contos que posteriormente seriam lidos e discutidos. Logo, eles foram orientados sobre seu uso e incentivados a realizarem seus registros.

Embora os diários não tenham sido recolhidos para análise da professora, foram utilizados como suporte para as discussões em sala de aula e, ao final do projeto, guiaram as discussões no grupo focal, reunião que funcionou como sistematização do processo vivenciado pelo grupo ao longo do desenvolvimento do projeto. Nesse contexto, os diários não tiveram caráter de instrumento avaliativo, mas operaram como memória das sensações e indagações surgidas no percurso das leituras realizadas.

$\mathrm{Na}$ reunião do grupo focal foi possível perceber reações afetivas, emocionais e psicológicas dos educandos no momento das discussões, pois, em suas falas, muitos se

\section{LINHA DÁGUA}


utilizavam de frases e trechos registrados no diário para defender seu posicionamento diante do texto, principalmente nos contos que não apresentavam desfechos felizes ou que levavam a algum tipo de desconforto, estranhamento, como pudemos observar em "Pai contra mãe", de Machado de Assis, e "O barril de Amontillado", de Edgar Allan Poe, cujos desfechos foram considerados desumanos, na categorização dos estudantes.

As capas dos diários, confeccionadas pelos educandos, refletiram esse estranhamento e nelas percebemos as impressões pessoais construídas a partir de cada narrativa ou as cenas que causaram um maior estranhamento. É o caso do que o ocorreu com a aluna J, pois, a partir de seu registro, pode-se visualizar elementos presentes nos contos "Uma vela para Dario", "Barril de Amontillado" e "Pai contra mãe", constituídos pelas figuras da vela e sangue, tendo acima o símbolo da justiça, em uma clara alusão à sua ausência nas narrativas mencionadas. Na capa também é possível ler a frase: "Se não se comove com sangue inocente no chão, quem 'cês' acham que são para ditar emoção?”, enunciado que expressa a força do impacto das obras na aluna.

Figura 1. Aluna J e seu diário de leitura.

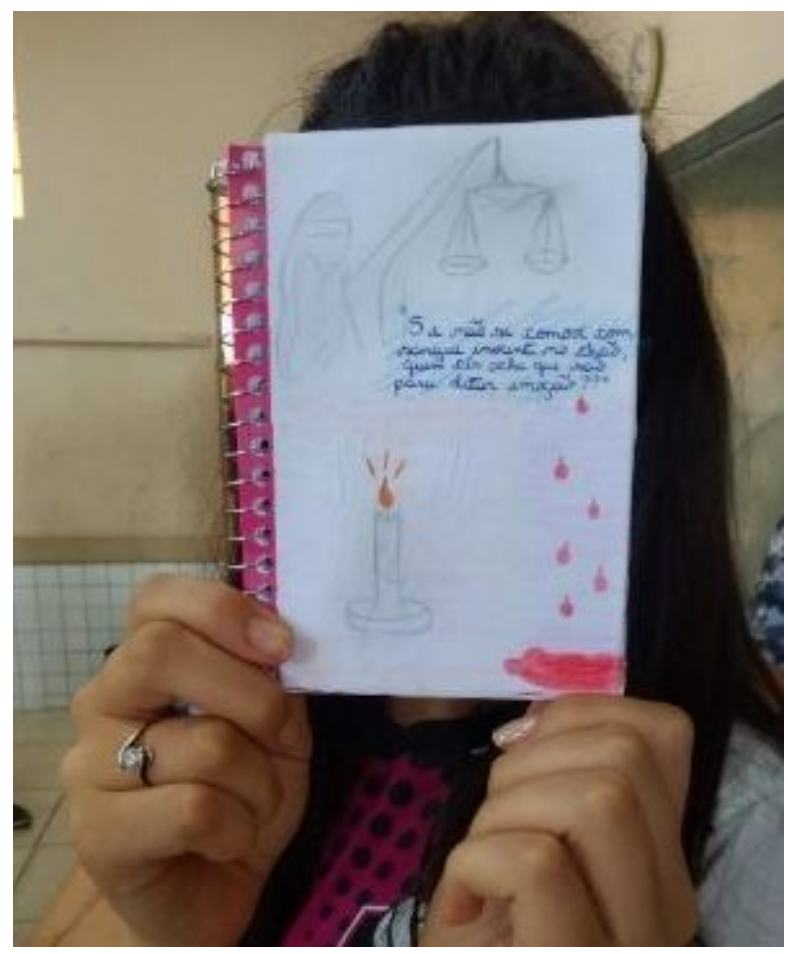

Fonte: Arquivo pessoal da professora (2019).

Quando questionada sobre os motivos que a levaram à escolha das imagens, a aluna destacou que a justiça não pode ser esquecida, tampouco o ser humano ser tratado como objeto, conforme aconteceu nos contos mencionados.

Na figura 2, percebemos que o aluno $\mathrm{P}$ enfatizou em seu diário de leitura alguns objetos dos contos estudados. Nele é possível perceber a referência à vela e ao guarda-chuva, elementos

\section{LINHA DÁGUA}


oriundos do conto "Uma vela para Dario", os elos de uma corrente remetendo à crueldade presente nas atitudes dos protagonistas da trama de "Pai contra mãe", uma teia de aranha, referindo-se a um lugar pouco visitado, como a sombria adega onde Fortunato é emparedado, no conto "Barril de Amontillado", de Poe.

Figura 2. Aluno P e seu diário de leitura.

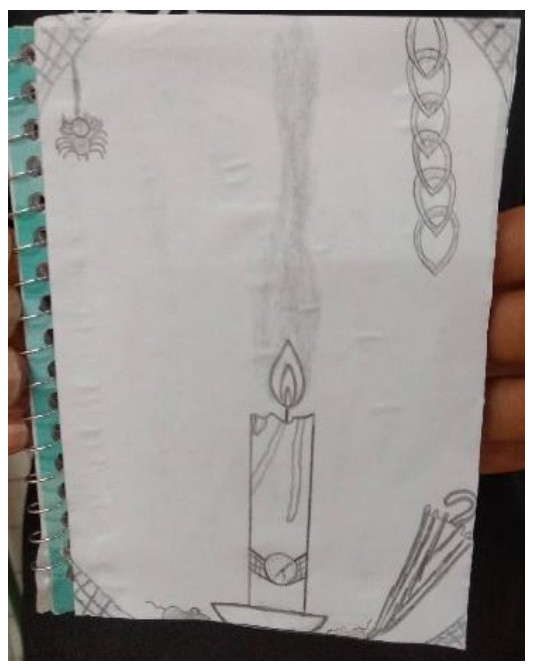

Fonte: Arquivo pessoal da professora (2019).

O aluno H, ao exibir sua capa já finalizada (Figura 3), destaca a imagem da morte, que, segundo o estudante, é recorrente nos contos. Percebemos também algumas figuras relacionadas a "Uma vela para Dario": o homem e a criança, uma referência clara à passagem que mais despertou sua atenção, na qual Dario, exposto ao espetáculo da morte, é observado pelo menino de pés descalços, que expressa piedade e compaixão pelo morto. A cena sensibilizou o aluno a ponto de reproduzi-la na capa do seu diário.

Figura 3. Aluno H e seu diário de leitura

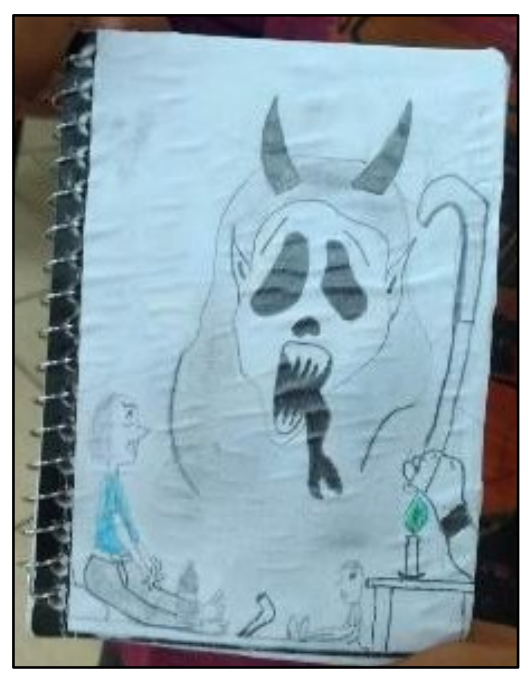

Fonte: Arquivo pessoal da professora (2019).

\section{LINHA DÁGUA}


À medida que os alunos realizavam anotações nos diários, ao trazer à tona as impressões e sensações experienciadas durante o ato de ler, observamos um maior envolvimento com a leitura. A prática possibilitou o diálogo entre leitor e texto, estabelecendo vínculo com a história, priorizando desta maneira, a leitura subjetiva e os múltiplos sentidos do texto.

\subsection{O diário de leitura no Ensino Superior: experiência subjetiva e formação docente}

No ano de 2019, no curso de Licenciatura em Letras-Português de uma universidade pública do Norte do Paraná, foi proposto como atividade a se desenvolver ao longo de todo o semestre, na disciplina de Leitura no Ensino Médio, o registro das leituras realizadas em um diário pessoal. Como regras básicas para a escrita do diário, orientou-se que fosse produzido em um suporte físico e que nele constassem anotações a respeito de todas as leituras feitas ao longo do semestre, fossem de textos teóricos ou de outras esferas discursivas, geralmente utilizados como objeto das discussões a respeito das práticas de leitura.

A ideia era colocar em ação uma experiência inovadora de formação leitora, partindo das propostas de Rouxel (2013b), conduzidas a partir de uma concepção de leitura que considera fortemente o dado afetivo no processo de leitura. Nesse sentido, os diários, apesar de realizados no contexto de uma disciplina acadêmica pautada em teorias, admitiam anotações de toda ordem e mesmo em linguagem não verbal. O objetivo principal, nessa lógica, não era aferir quantidade ou qualidade das leituras realizadas pelos alunos, mas colocá-los em estreito contato com uma metodologia desconhecida por eles e com potencial para ser implementada na educação básica.

Por se tratar de uma metodologia inovadora e ainda pouco conhecida no Brasil, os estudantes ficaram bastante inseguros em relação ao modo como o diário seria aproveitado no processo de aprendizagem e mesmo de sua avaliação. Por essa razão, optou-se por criar alguns critérios não só para sua produção, mas também para sua avaliação, de modo a tranquilizar os alunos e, sobretudo, conduzi-los a uma prática mais livre para os registros e até com vistas a uma leitura cursiva (ROUXEL, 2012), em certos casos.

Tendo em vista que o diário seria parte dos instrumentos de avaliação da disciplina, como dito, foi necessário demarcar alguns critérios para a sua "correção" (entre aspas, pois não se tratava de um instrumento que tivesse condições de apresentar erros ou acertos). Diante disso, optou-se por dois critérios, sendo um quantitativo e outro qualitativo. O primeiro dizia respeito à compatibilidade entre o número de registros realizados pelo aluno e o de textos lidos ao longo do semestre. $\mathrm{O}$ segundo critério configurou-se a partir da observação mais detida de ao menos um dos registros, não com o propósito de identificar erros - tendo em vista que não seria possível fazê-lo, já que o diário é uma livre produção do aluno -, mas buscando compreender mais aprofundadamente os processos vivenciados pelos estudantes durante a experiência de uso do diário.

\section{LINHA DÁGUA}


Vale retomar que, como o diário não objetivava a avaliação das leituras feitas pelos alunos, a solicitação da entrega tinha como propósito menos a tarefa realizada pelo estudante que a própria pertinência do diário enquanto instrumento de apoio na atividade leitora.

A escrita do diário teve grande adesão dos estudantes, sendo que todos a realizaram. Ademais, em seus depoimentos a respeito da experiência, realizados como parte das atividades de síntese do semestre, observou-se um grande número de relatos que considerava positivamente a experiência, conforme se verá nos excertos adiante.

As observações a respeito da experiência realizada com o diário de leitura na referida turma de Ensino Superior foram consubstanciadas por meio dos seguintes corpora: os conteúdos registrados nos diários, o tratamento estético dado ao suporte dos diários (cadernos) e as respostas dadas na atividade de síntese do semestre à proposta "Relate como foi a experiência de poder registrar sua leitura a partir de um investimento mais subjetivo".

O primeiro corpus analisado, isto é, os registros das leituras feitas, obedeceu aos mesmos critérios delimitados para a avaliação dos diários, isto é, quantidade de registros compatível com a de leituras feitas no semestre e a qualidade do registro, aferida a partir da análise de uma das anotações realizadas pelos alunos.

Quanto ao aspecto quantitativo, observou-se que os estudantes, em sua maioria, obedeceram à orientação e procuraram registrar a maior parte das leituras realizadas. Também foi notório que, na eventualidade da omissão de registros de leitura, era comum que estivessem ausentes os textos utilizados como objeto de estudo em sala de aula e não os que constavam das referências bibliográficas da disciplina. Vale dizer que, muito provavelmente, os diários que não contemplavam os textos lidos em sala de aula não tiveram seus registros realizados imediatamente após as leituras efetuadas. Também pelo fato de esses mesmos diários serem os mais enxutos em termos de quantidade e mesmo de aprofundamento dado aos registros, é possível inferir que tenham sido organizados ao final do semestre, mais com a perspectiva do cumprimento de tarefa avaliativa do que da experimentação do processo de subjetivação que a escrita do diário pode proporcionar.

No tocante ao processo de subjetivação, foi notável o cuidado expresso na escolha do suporte utilizado para os registros. De um lado, observou-se uma preocupação estética, aferida pela opção por cadernos delicados, por vezes até decorados pelos alunos. De outro, a não preocupação estética, vista, por exemplo, em diários cujo suporte era dado por um conjunto de folhas de caderno unidas por grampos e cujos textos vinham escritos a lápis. A fragilidade de um diário como esse também pode revelar algo sobre a leitura e sobre o lugar do sujeito nesse processo, embora não caiba aqui aprofundar em análises desse teor. Cabe apenas ressaltar que as opções mais ou menos articuladas esteticamente, ou mesmo marcadas por certa displicência, dão indicativos do lugar dado pelo estudante à experiência de leitura favorecida pela disciplina.

Sobre os conteúdos dos diários, ficou patente que os alunos se sentiram à vontade para expressar suas opiniões e apreciações. Ficou visível também que os textos menos apreciados

\section{LINHA DÁGUA}


eram registrados quase que protocolarmente, enquanto os mais impactantes resultaram em registros mais extensos e mais posicionados por parte dos estudantes.

Ainda em relação aos diários e ao espaço de subjetividade por ele garantido, chamou a atenção o registro de uma estudante que, tocada pelo efeito produzido a partir da leitura de $A$ importância do ato de ler, de Paulo Freire, colou uma fotografia que registra um momento especial de sua infầncia. A ação revela a legitimação do diário como espaço garantido para a expressão subjetiva, na medida em que a aluna se permite fazer um registro não verbal. Mais que isso, opta por fazer esse registro por meio de uma clara exposição de um em si, recôndito em sua história pessoal, e, talvez, manifestado apenas pelo fato de haver um espaço de liberdade para fazê-lo. Nesse sentido, o diário cumpre o que Rouxel (2012) aponta como o restabelecimento do "sujeito no coração da leitura" e o acolhimento na sala de aula de "suas reações, que irão orientar os processos interpretativos" (ROUXEL, 2012, p. 278). Mais ainda, o que se verifica na situação aqui relatada expressa o que Rouxel (2012), em consonância com Freire (2001), afirma: "É pelo vínculo estabelecido entre o universo da obra e o universo do leitor que o ato de ler ganha sentido e se inscreve na vida do sujeito" (ROUXEL, 2012, p. 278).

$\mathrm{Na}$ atividade de síntese, à questão sobre a experiência com o diário, diversos alunos fizeram considerações positivas. Alguns enunciados, nesse sentido, se destacam:

A. Gostei de prestar atenção nesses sentimentos pequenos, nas centelhas de lembranças, que acabei acessando e registrando em decorrência do diálogo que conseguia estabelecer em meu diário de leitura.

B. No registro de leitura posso perceber o surgimento do meu mais novo interesse: a leitura de HQs (...).

C. Poder ler e escrever o texto sem a pressão haver um certo ou um errado é libertador (...).

D. (...) tive a percepção de um "transbordamento da subjetividade", não só na leitura e na escrita do diário, mas também nas minhas opiniões dadas em sala de aula (...)".

Em A, é possível observar a apropriação da linguagem poética ("centelhas de lembranças") como recurso de expressão subjetiva, fenômeno bastante frequente em diários de leitura. Em B, também como expressão da subjetividade, o estudante registra a percepção a respeito de si, em pleno processo de formação leitora ("meu mais novo interesse"). Nos excertos $\mathrm{C}$ e $\mathrm{D}$, vemos a apreciação do diário enquanto um instrumento que possibilita um melhor aproveitamento das reflexões realizadas em aula, o que aponta para o seu funcionamento como ferramenta metodológica nas interações didáticas.

Conforme relatado, a experiência com o diário de leitura em uma turma do Ensino Superior, além de cumprir o objetivo de proporcionar o conhecimento empírico dessa ferramenta metodológica, também operou na compreensão da própria formação do aluno, enquanto leitor e mesmo como sujeito apto a se posicionar de forma autônoma nos espaços reflexivos da atividade acadêmica. Ademais, possibilitou a assunção de uma maior liberdade e, assim, maior segurança perante as leituras recomendadas nas disciplinas cursadas na universidade.

\section{LINHA D'́GUA}




\section{Considerações finais}

A partir das experiências relatadas, observamos que o diário de leitura representa um instrumento profícuo para o leitor expressar sua subjetividade, pois abre espaço para que registre o que sentiu e como se envolveu pessoalmente durante a leitura do texto literário ou oriundo de outras esferas, podendo retomar isso posteriormente. Entretanto, mais do que apreender os conteúdos das obras, buscamos com essa ferramenta, que os alunos se descubram enquanto leitores, seja testando, experimentando diversos tipos e estilos de textos, dos quais podem gostar ou não, seja demarcando as sensações que vivenciam e as reflexões que desenvolvem nesse processo.

Logo, é necessário compreender que é a leitura que o educando faz para si mesmo que tem o seu valor. É claro que o diário de leitura por si só não proporcionará isso, mas, utilizandoo em conjunto com outras estratégias, é possível ser um ponto de partida ou um bom auxiliar para as diversas propostas de atividade leitora nas instituições de ensino.

Notamos, entretanto, que, na prática 1 , o diário se configurou como um instrumento que precisaria ser explorado, tendo em vista que os alunos, até então, não pareceram ter se sentido à vontade para se colocar na escrita ou não se viram ainda autorizados a isso. Trata-se, portanto, de um aspecto do trabalho com a leitura que é difícil de operacionalizar, na medida em que é uma novidade para muitos estudantes, sendo necessário, portanto, um investimento do professor para acompanhar de perto tal escrita com parcimônia. No entanto, no ensino remoto, conforme acabou por ser conduzida a prática relatada, as dificuldades se multiplicam, dado que a proposta pode se perder entre tantas tarefas e situações novas, culminado numa visão equivocada, que a leva a ser considerada mais uma atividade obrigatória e constantemente cobrada. Logo, nem sempre os diários de leitura darão conta da experiência vivida pelo leitor durante o ato de ler, pois, têm suas limitações dentro de um ambiente institucionalizado como a escola. Apesar disso e do contexto em que foi aplicado, o diário trouxe elementos interessantes para (re)pensar as práticas de leitura na sala de aula, pois se apresentou como um instrumento eficaz para o professor apreender as particularidades do processo de formação de cada leitor e planejar as próximas leituras e propostas.

Na prática 2, percebemos que o trabalho sistematizado com o diário de leitura mostrouse muito oportuno para o desenvolvimento subjetivo da leitura de literatura, como apoio da mediação do professor, uma vez que envolveu os alunos nas práticas leitoras e nas discussões implementadas. Os textos lidos não se restringiram a avaliações e fichas de leitura, mas estabeleceram um diálogo entre a obra e as impressões pessoais dos educandos. Desse modo, os alunos mostraram-se interessados em participar das atividades e foram ganhando confiança para expor suas impressões sobre os contos lidos, inclusive demonstrando, por meio da linguagem não verbal, ou seja, pelos desenhos registrados nas capas dos cadernos, a sua interpretação e a implicação subjetiva no ato de ler.

\section{LINHA DÁGUA}


Ressaltamos que não existem caminhos prontos para trabalhar leitura na escola, tampouco métodos milagrosos para que isso aconteça. Diante disso, cabe ao professor buscar novas metodologias e oportunizar práticas que tragam à tona as impressões e sensações experienciadas durante o ato de ler, porque é de maneira compartilhada que o aluno também pode ampliar suas experiências, principalmente, no que tange à leitura de literatura. Nesse sentido, na prática 3, os graduandos tiveram a oportunidade de vivenciar o processo de leitura subjetiva, além de conhecer uma ferramenta que pode contribuir para sua prática pedagógica no futuro.

Por fim, enfatizamos que cada uma das experiências enfoca algum aspecto possível do uso do diário de leitura, os quais podem ser transpostos para sala de aula, seja na Educação Básica ou em cursos de licenciatura.

A leitura, tanto da obra literária como daquelas oriundas de outras esferas discursivas, tem papel fundamental na elaboração da subjetividade do leitor, assim como, na construção dos círculos de pertencimento, como afirma Petit (2009). A maneira pela qual um leitor imagina as cenas e as personagens de uma obra remete aos acontecimentos que vivenciou, uma vez que, o plano afetivo e o plano intelectual, considerados tradicionalmente como constitutivos do ato de ler, são afetados pela subjetividade. Do mesmo modo, a apropriação de um conceito teórico, que toca diretamente a vivência do indivíduo, também tem potencial para afetá-lo subjetivamente, levando-o a uma compreensão mais intensa e profunda dos conteúdos de uma obra. Nesse sentido, finalizamos nossa reflexão, relembrando Jouve (2013), que defende subjetividade no ensino, na medida em que ela deve ser reconhecida como um componente imprescindível no processo de leitura.

\section{Financiamento}

Tatiele Jesus Faria agradece à Coordenação de Aperfeiçoamento de Pessoal de Nível Superior (CAPES) pelo financiamento da pesquisa (Número do processo: 5714775).

\section{Referências}

ANDRUETTO, M. T. A leitura, outra revolução. Tradução de Newton Cunha. São Paulo: Edições Sesc São Paulo, 2017.

FARIA, T. J. Letramento literário como incentivo à formação do leitor crítico: volume I. Orientadora: Sheila Oliveira Lima. Londrina, 2020. 103 f. Dissertação (Mestrado em Profletras) - Universidade Estadual de Londrina, Londrina, 2020.

FREIRE, P. A importância do ato de ler. São Paulo: Cortez, 2001.

JOUVE, V. A leitura. Tradução de Brigitte Hervot. São Paulo: Unesp, 2002.

\section{LINHA D'́GUA}


JOUVE, V. A leitura como retorno a si: sobre o interesse pedagógico das leituras subjetivas. In: ROUXEL, A.; LANGLADE, G.; REZENDE, N. L. (Orgs.). Leitura subjetiva e ensino de literatura. Tradução de Amaury C. Moraes et al. São Paulo: Alameda, 2013. p. 53-65.

LANGLADE, G. O sujeito leitor, autor da singularidade da obra. In: ROUXEL, A.; LANGLADE, G.; REZENDE, N. L. (Orgs.). Leitura subjetiva e ensino de literatura. Tradução de Amaury C. Moraes et al. São Paulo: Alameda, 2013. p. 25-38.

PASTORELLO, L. M. Leitura em voz alta e produção da subjetividade: um caminho para a apropriação da escrita. São Paulo: Edusp, 2015.

PETIT, M. Os jovens e a leitura: uma nova perspectiva. 2. ed. Tradução de Celina Olga de Souza. São Paulo: 34, 2009.

ROUXEL, A. Práticas de leitura: quais rumos para favorecer a expressão do sujeito leitor? Tradução Neide Luzia de Rezende e Gabriela Rodella de Oliveira. Cadernos de Pesquisa. v. 42, n. 145, p. 272-283. jan./abr. 2012. Disponível em: https://www.scielo.br/pdf/cp/v42n145/15.pdf. Acesso em: 12 fev. 2021.

ROUXEL, A. Apropriação singular das obras e cultura literária. In: ROUXEL, A.; LANGLADE, G.; REZENDE, N. L. (Orgs.). Leitura subjetiva e ensino de literatura. Tradução de Amaury C. Moraes et al. São Paulo: Alameda, 2013a. p. 163-189.

ROUXEL, A. Autobiografia de leitor e identidade literária. In: ROUXEL, A.; LANGLADE, G.; REZENDE, N. L. (Orgs.). Leitura subjetiva e ensino de literatura. Tradução de Amaury C. Moraes et al. São Paulo: Alameda, 2013b. p. 67- 87.

TODOROV, T. A literatura em perigo. Tradução de Caio Meira. Rio de Janeiro: Difel, 2007.

Recebido: 27/04/2021.

Aprovado: 02/08/2021. 